2002

\title{
In-Between Science and Religion
}

Dominic Balestra

Fordham University, balestra@fordham.edu

Follow this and additional works at: https://fordham.bepress.com/phil_research

Part of the Philosophy of Science Commons

\section{Recommended Citation}

Balestra, Dominic, "In-Between Science and Religion" (2002). Research Resources. 44.

https://fordham.bepress.com/phil_research/44

This Article is brought to you for free and open access by the Hermeneutic and Phenomenological Philosophies of Science at DigitalResearch@Fordham. It has been accepted for inclusion in Research Resources by an authorized administrator of DigitalResearch@Fordham.

For more information, please contact considine@fordham.edu. 


\section{DOMINIC BALESTRA}

\section{IN-BETWEEN SCIENCE AND RELIGION}

\section{METHODOLOGICAL DEMARCATION: A WANING WALL}

Stripped of its seventeenth and eighteenth century Deistic, if not theistic, sensibility, science entered the twentieth century as agnostic and indifferent, if not outrightly antagonistic, toward religion. Religion was often viewed as the enemy of modern science; and its theology was presumed to be intellectually vacuous. "Real science" was clearly understood to be objective, empirical and rational. It bore no relationship to theology, none of any cognitive import - except perhaps to eliminate theology as contributing toward any understanding of the cosmos. This view of the relationship between science and religion was further reinforced by logical empiricism. In the latter's view science aimed to establish empirically testable, generalized explanations of observable but problematic phenomena. Such phenomena might be freely falling bodies or the deviation of a planet from the expected path of its usual orbit. As the phrase "logical empiricism" suggests, in its view the objectivity of science rested with an evidential base of empirical facts, facts which were independent of any hypothesized theory under question and available to all through sense observation. And the rationality of science was ascribed to the logical testability of its explanatory hypotheses.

The rationality and objectivity of science was synonymous with, respectively, logicality and empiricism. Only those aspects of science amenable to this model of objective rationality, features internal to what was called the "context of justification," were of cognitive significance. Social, economic or psychological factors in the genesis of a hypothesis, such as for example, the development of nineteenth thermodynamic theory as motivated by the central role of the steam engine in the industrial revolution, were considered irrelevant to the question of whether a theory was true or rationally warranted. In general, such social and historical dimensions of science were relegated to a distinct "context of discovery" which was presumed to be external to science qua knowledge. In this way the agnostic or atheist could square with history and acknowledge the role of religious motives in the founding fathers, most notably Galileo, Kepler, and Newton, for whom the vocation of the natural philosopher was to read the mind of God in the Book of Nature.

This portrait of scientific knowledge grew out of the modern dogma of a fact/value dichotomy, which relegated questions of ethics, values and the meaning of life to a 
subjective sphere alien to the fact world of science. Indeed, armed with its verifiability principle of meaningfulness, logical empiricism reinforced the treatment of questions of ethics as nonrational matters for meta-ethical analysis of feelings and emotions, and it prohibited theology, revealed or natural, as meaningless assertions construed as emotive expressions of "wish fulfillment" or the absurdity of our place in the universe. With few exceptions philosophical treatment of science and religion was quite sparse. For the most part philosophy sought to demarcate science in order to protect it from metaphysics, especially of the religious kind. Even though Karl Popper recognized the folly of rendering metaphysics as meaningless and rejected logical empiricism's theory of meaning, he insisted upon a demarcation of science from metaphysics in order to display the superiority of scientific rationality.

Popper's position rests upon two, closely related themes in the philosophy of science: one, the logicist thesis that rationality is logicality; and two, the demarcation thesis which asserted that as a result of the rationality thesis, science is distinctively privileged as an intellectual enterprise. All other intellectual disciplines - ethics, history, political theory, and social sciences (but not theology which was usually excluded as intellectually unacceptable) were considered more or less rational to the extent that they could exhibit the pattern of scientific rationality as understood according to these two theses. As a result of the work of Toulmin, Kuhn, the later Popper and Lakatos among others, these two themes collapsed under the weight of a much more historically minded, critical scrutiny of the theory of science.

The first thesis, that rationality is logicality, asserts that the rationality of science ultimately rests with its methodology, the so called hypothetical-deductive method of modern science. And this method is a means of logically testing a scientific hypothesis (proposed as a universal explanatory theory of a problematic phenomenon) by reference to a firm, objective base of empirical fact; and the second, the demarcation thesis held that such empirical testability essentially distinguishes a scientific hypothesis from a non-scientific one.

Insofar as scientific theories include universal statements, inductive logic (as Hume had argued) can not establish scientific laws and theories as true, logically speaking even the best confirmed and long established theories could be false. This logical feature of induction combined with the fact that the history of science exhibits confirmed theories which subsequently come to be rejected, provides a strong case that the theories of science are fallible and so only provisional or tentative. Early in his work Karl Popper recognized and argued for such fallibility of all scientific theories. Accordingly, he asked, whence the rationality of science?

Having rejected the inductivist construal of the method of science, Popper exploited a basic feature of deductive logic, viz., though a universal statement can not be demonstrated as true on the basis of a finite number of experimental confirmations, a universal assertion (All S are W) could be proven false by a single, contradictory statement (some $\mathrm{S}$ is not $\mathrm{W}$ ). Armed with this fact of logic, Popper developed the theme that although science is at best conjecture, it is rational conjecture precisely because it submits its plausible, conjectured theories to severe attempts at falsification by critical experiment. In Popper's own words, "only the falsity of the theory can be inferred from empirical evidence, and this inference is a purely deductive one."1 Accordingly, the rationality of science consists in a critical process of bold conjecture and critical refutation. Having interpreted the H-D method of scientific testing as a 
logic of falsification, Popper revised the demarcation thesis to read: "the criterion of the scientific status of a theory is its falsifiability, or refutability, or testability." ${ }^{2}$ In spite of this strong statement of falsifiability, Popper argued for other theses which reveal a much more subtle falsifiability, one which Lakatos called sophisticated methodological falsificationism. Two of these theses are: one, the primacy of theory over observation (this is akin to the Kuhnian thesis that all observations are theoryladen, there are no theory neutral facts); and two, the logic of the problem-situation, which maintains that the critical method of conjecture and refutation only has significance in the context of a clearly formulated and shared problem-situation. Thus, science conjectures theories as proposed solutions to problems and to the extent that the conjecture survives critical attempts to refute it, we may rationally accept the theory, at least until a better rival is proposed and both are put to a test. Furthermore, the rational assessment of rival theories is predicated upon a shared problem-situation.

A major line of argument against falsifiability originates with Pierre Duhem's thesis of the non-falsifiability of isolated scientific hypotheses. In his words: "In sum, the physicist can never subject an isolated hypothesis to experimental test, but only a whole group of hypotheses; when the experiment is in disagreement with his predictions, what he learns is that at least one of the hypotheses constituting this group is unacceptable and ought to be modified; but the experiment does not designate which one should be changed." 3 The "whole group," to which Duhem refers, involves a complex network which includes: background knowledge, "hard core" theories (e.g, Aristotle's two domain laws of natural motion or the three laws of motion in Newton), auxiliary hypothesis (such as explain the workings of the radio telescopes in astronomy and legitimate the "observed results" as evidence), and the hypothesis under test. The logic of falsification cannot target the hypothesis under consideration nor compel its rejection. The logic can guarantee only that somewhere something is amiss. It does not tell us where to look, or how to locate the source of the trouble. Indeed, one could introduce new auxiliary hypotheses in order to absorb the shock of failure and to immunize against the otherwise fatal effects of a recalcitrant experiment. For example, one of the objections to the Copernican theory which requires the earth to rotate at about one thousand mile per hour, was the "recalcitrant" result that a body falling from a high tower did not land sufficiently far to the west of the tower. Galileo responded to this by conjecturing his theory of circular inertia as an auxiliary hypothesis to explain the apparent anomaly. Though Galileo's circular inertia was mistaken, the tower problem generated the development of a series of hypotheses of inertia, by Descartes, Huygens, and Newton. The sequence of such auxiliary hypotheses is designed to "protect" some fundamental theoretical principles. The latter is similar to Kuhn's paradigmatic theory or Lakatos's "hard core" of the research program. Sooner or later the series of auxiliary hypotheses, which Lakatos appropriately named the "protective belt," must exhibit some corroborated empirical results, otherwise it risks being judged as ad hoc. The subsequent development of the protective belt generates, in programmatic response to various problems for the "hard core" and possibly subsidiary principles, a complex historical series of subsidiary theories which retains the "hard core." Lakatos named this historical series a scientific research program. In the case of scientific cosmology, the "hard core" of Hoyle's research program is the Steady-State theory in contrast to the Expanding Universe theory of the Big Band proponents. Hoyle responded to Hubble's observation of the red shift and its prima facie support of an expanding universe, with 
an auxiliary hypothesis of the constant ratio of the rate of expansion to the density of matter. The Steady State theory and the Big Bang theory emerged as rival research programs, and in time the Big Bang exhibited the empirical results that have made it the accepted theory today. The case of the eventual acceptance of the Big Bang theory exhibits two important features of the rationality functioning in the methodology of a scientific research program: one, no logically simple test from one result decided the question; and two, that "rational assessment" is in terms of sequenced problem-shifts which are the outcome of a programmatic, historical sequence of conceptual and experimental results. Today's philosophy of science recognizes that there is no ahistorical instant rationality of an abstracted hypothetical-deductive logic of testing. It is in the retrospect of history that the rationality of the theory choice can be judged. Moreover, given the provisional status of any theory and the theory-laden nature of empirical observations, it becomes clear that the rational judgment, even in the light of history, is not exclusively due to a logic of testing the research program against a pure empirical evidential base. However, it does not follow that a logic of experiments is not an essential part of rational theory choice, only that logic is not enough. Despite its brilliance Lakatos' development of methodological falsificationism does not succeed in eradicating the subject's judgment in the rational appraisal and choice of theories. The judgment of the experienced scientist, like Aristotle's phronesis in the individual's moral judgment, is an essential aspect of scientific rationality. Pierre Duhem recognized this at the end of his penetrating analysis of crucial experiments and his argument for non-falsifiability where he concludes

The sound experimental criticism of a hypothesis is subordinated to certain moral conditions; in order to estimate correctly the agreement of a physical theory with the facts, it is not enough to be a good mathematician and skillful experimenter; one must also be an impartial and faithful judge. ${ }^{4}$

Since Duhem first argued his thesis, subsequent philosophers of science (most notably W.V. Quine, Thomas Kuhn, and Imre Lakatos) have developed its argument and expanded its thesis. And even Karl Popper, the champion of falsifiability, has successively revised his position in response to Duhemian criticisms such that it more and more resembles that of Lakatos. In a later work, Objective Knowledge, Popper locates the heart of scientific rationality with the progress achieved in advancing the problem-situation. In his words: "[P]rogressiveness is one of the things we demand of a good tentative theory: and it is brought out by the critical discussion of it: the theory is progressive if our discussion shows that it has really made a difference to the problem we wanted to solve; that is, if the newly emerging problems are different from the old ones." 5

The clear result is that the distinctive advantage of modus tollens for the logicist thesis is diminished and the Popperian program of falsification is no longer tenable. Its sharp demarcation thesis wanes, and history enters into its rationality. Kuhn and Quine, Lakatos and Laudan, Newton-Smith and even Feyerabend, have in each's respective way developed a Duhemian philosophical program for enlarging the functioning unit of rational appraisal from a single isolated hypothesis to a complex, programmatic network of theories (conjectured in response to a core problem) variously characterized as paradigm, conceptual scheme, research program, research tradition and even a Wittgensteinian "form of life." 
Even if we were to distinguish between an isolated test statement and a contextualized test statement, and identify the latter as the potential "falsifier," the rational import gained could not be restricted to a sharply demarcated scientific context. For as conjectural, such theory-laden statements are fallible and therefore provisional. Accordingly any demarcation of science predicated upon falsifiability can only be a matter of degree and in terms of its historical situation. Now we see that the rationality of science is a highly complicated, historically situated process of critical discussion among inquirers in an open communication, something more like the kind of rationality Popper has always recognized as operative in good philosophy. In Conjectures and Refutations he responded to his own question of the rational assessment of irrefutable, metaphysical theories, asserting "[E]very rational theory, no matter whether scientific or philosophical, is rational in so far as it tries to solve certain problems. A theory is comprehensible and reasonable only in its relation to a given problem-situation, and it can be rationally discussed only by discussing this relation." Thus, the demise of falsifiability does not entail the irrationality of science; rather it reforms scientific rationality by locating it in a wider genus of criticizability, and thereby, replaces the formula of "conjecture and refutation" by "conjecture and critique." In accord with Popper this criticizability is always historically situated, but pace Popper it retains the Duhemian insight that the subject's judgment is an essential aspect of scientific rationality.

\section{RATIONALITY OF SCIENCE AND RELIGION: A MATRIX IN-BETWEEN}

In this reform, even in the wake of demarcation there still survives an unmistakable feature always at the heart of Western rationality: that a rationally acceptable theory, doctrine, interpretation or whatever appropriate unit of the disciplinary inquiry, is one which has withstood the critique of the discipline as a proposed answer to the questions posed by the problematic shared by members of the discipline. Obviously, though Popper did not anticipate it, this opens a Popperian standpoint to reconsidering the disciplinary rationality of theology, revealed or natural. Indeed, in his discussion of rationality and tradition there can be no doubt that the matrix of scientific rationality is a tradition. He says: “... 'science' is differentiated from the older myths not by being something distinct from a myth, but by a second-order tradition - that of critically discussing the myth." " In so far as a theology is a tradition of critical consideration and discussion of the religious myths passed on from one generation to the next, a theological, disciplinary enterprise need be no less rational than a scientific one. ${ }^{9}$

In spite of Popper's attempts to objectify the norms of rational assessment in such a way that no appeal to the subject is needed for rational choice, ${ }^{10}$ an important corollary to the preceding discussion of rationality and demarcation is that in intellectual questions regarding theology or science the respective judgments of the experienced scientist or the experienced theologian are ineradicable to their traditions as rational. It then follows that the judgment of the individual who is experienced as both scientist and theologian is especially desirable in the dialogue between theology and science. Methodological results of the philosophy of science have removed a dense wall which divided modern science and theology. No doubt its recent fallout has helped create a climate much more hospitable to moving across disciplines in dialogue about the big questions. And the recent revival of such big questions in physics and biology have 
charged the atmosphere with some exciting prospects for shared understanding. At the same time these developments when set in a larger historical context advise caution. Theology should remember the legacy of Galileo's struggles with a theology which had yoked itself with the science of Aristotle. Today philosophy of science is virtually unanimous about the fallible and so provisional status of all scientific theories. Our methodological finding underscores the lessons of history. Does this mean that science as provisional knowledge and theology as "eternal" revelation can only meet at the end of history with nothing to exchange between now and then?

The last twenty-five years has witnessed a profusion of provocative exchanges across the science-religion divide which range from critical conflict to open dialogue or even attempts at some kind of convergence. Theologian and physicist, Ian Barbour, offers a useful classification which offers a reflective perspective from which to address the above question. In brief, Barbour partitions the possible relationships between science and theology into four basic types: Conflict, Independence, Dialogue, and Integration. The scientific reductionism of Jacques Monod's Chance and Necessity and Edward Wilson's sociobiology ${ }^{11}$ represent instances of a "scientism" which inevitably leads to a conflict with theology. By excluding any other knowledge as valid, and adding the a priori lemma that there is no God (because the web of science can not recover any God), then there can be no rational room for any theology, revealed or natural. On the side of religion, as we have seen in the case of "creationism", naive literalist readings of Scripture invade the disciplinary integrity of the sciences. There can be no tolerance from either perspective for due to naive literalism in the theology and naive realism and methodological chauvinism in the sciences, confrontation and conflict are inevitable.

The demarcation between the language of science and the language of theology initiated by Galileo eventually developed into Kant's epistemological dualism. It is a good illustration of the Independence type of relationship between science and theology. Each discipline with its respective autonomy with nothing to say to each other. But for Kant it was at the price of laying claim to a truth about reality in itself, whether it would be about the starry skies above us or the word of God within! In an interesting way both of these types share a naive realist perspective regarding reality and our knowledge of it. Both presuppose that the metaphysics of science or theology is all or nothing, that it insures complete and final knowledge of reality or all inquiry is in vain. For such a transcendental standpoint, there is no in-between. But recent philosophy of science says, with virtual unanimity, that our science is by its very nature historical, incomplete and thereby provisional. Accordingly, we find both the Conflict view and the Independence view unacceptable because of the metaphysical dogmatism each presupposes. This conclusion may not be obvious in the case of the Independence view. For one might subscribe to disciplinary autonomy without claiming complete or permanent knowledge, conceding that our current science is provisional and incomplete. But what would this imply? A pluralism, but which is itself provisional and for which the possibility of convergence, or an authentic dialogue, between science and theology in the long run, can not be excluded.

The last two categories, Dialogue and Integration, represent positions more in line with the tension-filled road out of Rome, of a fides quaerens intellectum. Because of the provisional and incomplete nature of the findings of science, the Dialogue view cautiously restrains any premature integration at either a substantive level or a 
methodological level. It recognizes sufficient parallels between the disciplines to warrant a dialogical relation between science and theology. In this relation it is usually theology reformulating its understanding of a basic doctrine, such as creation, in light of the best current knowledge from science. But it also recognizes disciplinary differences which require respecting the integrity of the distinct disciplines. Representatives of the Dialogue view are Wolfgang Pannenberg, Ernin McMullin, John Polkinghorne, and I suspect Patrick Heelan.

The last category, Integration, holds that some sort of integration between the content of science and theology is possible. Barbour distinguishes three versions of Integration. One version is a "natural theology" which claims that the existence of God can be inferred, at least as a plausible hypothesis (Richard Swinburne), from the evidence of design in nature which science discovers. Like the eighteenth "physicotheology" which it resembles, this natural theology is vulnerable to unexpected findings in science which might conflict with the basic theological claims. The second version is a "theology of nature" which in appropriating scientific theories within its otherwise distinctly theological concepts may reformulate its understandings of basic theological doctrines, such as that of creation. The Jesuit paleontologist Teilhard de Chardin's The Phenomenon of Man readily comes to mind as an example of a theology of nature. More recently the current theologian and biochemist Arthur Peacocke works a critical realist approach to develop a theology of nature. A major issue for the theology of nature is the nature of God's creative action: is it a continuous creation with God as remote but primary cause? Or, is it a deistic like plan initiated and implemented into a proximate chain of secondary causality, the domain of scientific study? The third version of Integration, "systematic synthesis," is a comprehensive metaphysics which incorporates contributions from both science and theology into a coherent worldview. The process metaphysics of Alfred North Whitehead exemplifies this version of integration. It is interesting to note that each version of integration represents a standpoint which works the integration respectively from science to theology, from theology to science, and from both science and theology into an "overriding" metaphysics. In every case theology is affected by science, in the "natural theology" even the data of theology may be construed as derived from the findings of science. In the latter two versions, theology's understandings of the data of theology may be affected by science. But are the concepts or theories of science ever reformed as a result of theological developments? No example comes readily to mind. A way may be through an indirect route, made possible by theologies subsumption within the more comprehensive, integrative metaphysics. A way which seems quite Hegelian and which places a philosophical metaphysics in a privileged position vis a vis science and theology. But if an Anglo-American philosophy of science calls for a historically situated scientific rationality which requires a turn to the Duhemian judgement of the subject, it is an ironic call for something like the standpoint of Patrick Heelan's hermeneutical phenomenology ${ }^{12}$ to address the in-between of science and religion.

\section{NOTES}

Fordham University

Karl Popper, Conjectures and Refutations (New York: Harper \& Row, 1963), 55.

Popper, Conjectures and Refutations, 37. 
3 Pierre Duhem, The Aim and Structure of Physical Theory, translated from the 1914 French edition by Wiener (New York: Atheneum Press, 1954), II, ch. VI, 180-90.

4 Duhem, The Aim and Structure of Physical Theory, ch. VI, "Physical Theory and Experiment," p.218. First published in French, 1906.

5 Karl Popper, Objective Knowledge ((New York: Oxford University Press, 1972), p.288.

6 See W.H. Newton-Smith, The Rationality of Science (London: Routledge \& Kegan Paul, 1981), chs. III - VI for a critical examination of this development in Popper, Lakatos, Kuhn, and Feyerabend. A more recent, but briefer, presentation of the development of the unit of scientific rationality is provided by Ernan McMullin, "The Shaping of Scientific Rationality," in E. McMullin, ed., Construction and Constraint: The Shaping of Scientific Rationality, (Notre Dame: University of Notre Dame Press, 1990).

7 Popper, Conjectures and Refutations.

8 Ibid., ch. 4, "Towards a Rational Theory of Tradition," 127.

9 See Nancy Murphy, Theology in an Age of Scientific Reasoning, (Ithica, NY: Cornell University Press, 1990) for an exemplary treatment of a theological rationality which parallels scientific rationality. For an up to date comprehensive treatment of a "postfoundationalist" rationality across the disciplices of science and theology see J. Wentzel van Huyssteen, The Shaping of Rationality: Toward Interdisciplinarity in Theology and Science, (Grand Rapids, MI: Wm. B. Eerdmans, 1999).

10 Karl Popper, Objective Knowledge, see especially ch. 3, "Epistemology Without a Knowing Subject," $106-52$.

11 Despite Edward O. Wilson's more recent and more sophisticated appreciation of the philosophical presuppositions of his evolutionary enterprise, he begins Consilience: The Unity of Knowledge, (New York: Alfred A. Knopf, 1998) pleading guilty to anticipated charges of "ontological reductionism, scientism" only to dismissively call for moving on! 11.

12 A good place for Anglo-American philosophers to enter Heelan's hermeneutical philosophy of science is Ch. 1, "Phenomenology, Hermeneutics, and Philosophy of Science," and Ch. 13, Hermeneutics and the History of Science," in his work Space-Perception and the Philosophy of Science (Berkeley: University of California Press, 1983). 